\title{
Quadricuspid aortic valve: an unexpected echocardiographic finding
}

\author{
Carlos Manuel Aboitiz-Rivera ${ }^{1,2}$, Ruben Blachman-Braun², Mario Fernando Lanza ${ }^{2}$, \\ Roberto Berebichez-Fridman², María José Díaz-Huízar², Laura Graciela Ferrer-Arellano², \\ Alejandra Andrea Ramírez-Freyre², Mario Enrique Baltazares-Lipp ${ }^{1}$
}

${ }^{1}$ Servicio de Hemodinamia y Ecocardiografía, Instituto Nacional de Enfermedades Respiratorias (INER), Tlalpan, Distrito Federal, México ${ }^{2}$ Facultad de Ciencias de la Salud, Universidad Anáhuac México Norte, Edo. de México, México

\begin{abstract}
Quadricuspid aortic valve (QAV) is an anatomic valvular variant, with a prevalence of $0.008 \%$ to $0.033 \%$ in the general population, and $1.46 \%$ in patients that undergo aortic valve replacement. The QAV can be an isolated valvular abnormality or associated with other congenital heart defects. In this article, we present three of the few reported cases of QAV in the Hispanic population, all of which were asymptomatic and without evidence of hemodynamic alterations or other associated heart defects. Additionally a literature review is provided.
\end{abstract}

Keywords: Quadricuspid aortic valve, congenital heart defects, echocardiography.

\section{Introduction}

Quadricuspid aortic valve (QAV) is an anatomic valve variant, first described by Balington in $1862[1,2]$. The reported prevalence ranges from $0.008 \%$ to $0.033 \%$ in the general population; however, the incidence increases up to $1.46 \%$ in patients that undergo aortic valve replacement [3]. This anatomic anomaly, although is usually considered to be a solitary finding, can be associated with other malformations, such as patent ductus arteriosus [4], ventricular septal defect, pulmonary stenosis, hypertrophic cardiomyopathies [1], subvalvular and supravalvular aortic stenosis with left coronary atresia, and coronary ostia obstruction in nearly $10 \%$ of the cases.

Even though the precise etiology of QAVs remains unknown, several hypotheses have been postulated; among them an abnormal separation of the conotruncus

Received 28.08.2015 Accepted 16.09.2015

Med Ultrason

2016, Vol. 18, No 2, 250-252

Corresponding author: Ruben Blachman-Braun

Facultad de Ciencias de la Salud,

Universidad Anáhuac México Norte,

46 Av. Universidad Anahuaca,

Col. Lomas Anáhuac, Huixquilucan,

Edo. de México, C.P. 52786, México

Phone: $+52(55) 56270210$

Fax: $+52(55) 55961938$

E-mail: rubenblach@gmail.com by the septum, excavation in any of the valve cushions, and septation of normal valve cushions resulting from an inflammatory process [5]. According to Fernández et al, a four-leaflet valve can occur from a supernumerary cushion resulting from division of one of the three mesenchymal precursors that form each normal cusp [6].

In 1973 Hurwitz and Roberts [7], described and classified the quadricuspid semilunar valves in 7 different groups from A to $\mathrm{G}$ according to the morphologic characteristics and the size of each of the four cusps of the valve (Table I). After reviewing the literature, Timperley et al [5] reported that the most frequent QAV type is B, followed by $\mathrm{A}$ and $\mathrm{C}$, and similar results were reported by Bakirci et al [8] Additionally, quadricuspid pulmonary valves are 9 times more frequent than QAV [5].

Table I. Hurwitz and Roberts classification of the quadricuspid semilunar valves [7].

\begin{tabular}{ll}
\hline Type & Description \\
\hline A & Four equal cusps. \\
B & Three equal cusps and one smaller cusp. \\
C & Two equal larger cusps and two equal smaller cusps. \\
D & One large, two intermediate and one small cusp. \\
E & Three equal cusps, one larger cusp. \\
F & Two equal larger cusps and two non-equal smaller cusps. \\
G & Four unequal cusps. \\
\hline
\end{tabular}


Due to the limited amount of available publications regarding the epidemiology and diagnosis of QAV in the Hispanic population [1], the clinical, morphological and echocardiographic presentation of the diagnosis of three cases with QAV are reported and a literature review is also provided.

\section{Case report 1}

A 15 year-old female patient presenting obstructive sleep apnea syndrome (OSAS) was referred by the pulmonology department. Physical examination showed unremarkable cardiac exam and did not suggest other pathologies. An echocardiogram showed an aortic ring of $21 \mathrm{~mm}$ in diameter with a QAV type G; the ejection fraction (EF) was $67 \%$. Other structural anomalies or hemodynamic alterations were not found (fig 1).

\section{Case report 2}

A 7 year-old male patient, diagnosed with OSAS, was referred for evaluation. At the time of the interview, the parents denied any important past medical history. Physical examination was unremarkable, and no alteration during heart auscultation was found. Echocardiography revealed a QAV classified as category B with an aortic ring of $20 \mathrm{~mm}$ in diameter and an EF of $75 \%$, aortic regurgitation was not found. The rest of the study was unremarkable (fig 2).

\section{Case report 3}

A 30 year-old female patient, diagnosed with pneumonia, referred no significant past medical history and no suspicion of other pathologies on physical examination. Echocardiography showed a QAV classified as type B with a $23 \mathrm{~mm}$ aortic annulus and an EF of 56\%. Pulmonary hypertension was detected, with a systolic pulmonary pressure of $42 \mathrm{mmHg}$ and a maximal gradient of $33 \mathrm{mmHg}$ (fig 3).

\section{Discussions}

QAVs can be presented as an isolated valve abnormality, or associated to other congenital heart defects or systemic malformations [9]. The main differential diagnosis of QAV is pseudo QAV's that result from rheumatic fever or other severe bacterial infections, and can be distinguished by the detection of the Arantii nodules in the valve's cusps [5].

The most common functional complication associated with QAV is aortic regurgitation [10,11]. More than

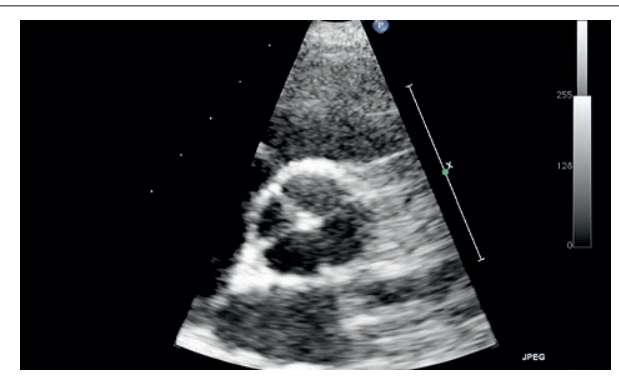

Fig 1. Echocardiographic study showing the QAV of case 1 .

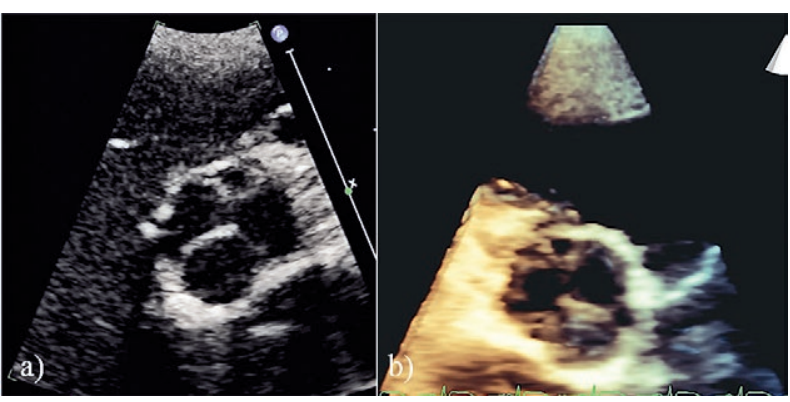

Fig 2. a) Transthoracic echocardiographic study showing the QAV of case 2, B type; b) 3D echocardiographic reconstruction of the QAV.

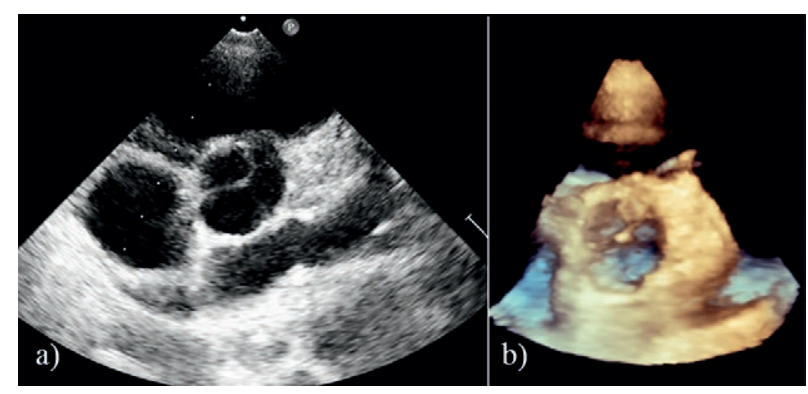

Fig 3. a) Transthoracic echocardiographic study showing the QAV of case 3, B type; b) 3D echocardiographic reconstruction of the QAV.

$50 \%$ of patients will progress to aortic insufficiency in adulthood [12]; however, the incidence is lower in type A [5]. Aortic regurgitation develops from fibrous thickening of the cusps, incomplete leaflet coaptation, and mechanical stress consequence of cusp asymmetry [4,8].

Tutarel et al, analyzed 186 patients with QAV and found that $74.7 \%$ presented aortic regurgitation, while a small percentage had combined valve regurgitation and stenosis, and one case with aortic stenosis: only $16 \%$ had normal valve function. In addition, $18.3 \%$ of patients had other congenital cardiac defects, most commonly anomalies of the coronary arteries [13]. This was consistent with the results of Gouveia et al that reported that $10 \%$ of the patients with QAV had coronary artery anomalies [14]. 
QAVs are rarely diagnosed since most of the patients are asymptomatic and present no hemodynamic alterations or other associated cardiac anomalies. This information is compatible with the clinical picture of the cases reported in this article. Initially, QAVs were diagnosed during surgery or autopsy; nonetheless, the introduction of non-invasive techniques, such as echocardiography, has improved the preoperative diagnosis, as other abnormalities can be associated [5]. Trans Esophageal Echocardiography (TEE) on short-axis view has become convenient for the confirmation of QAV where an X-shaped pattern during diastole and a rhomboidal image in systole are the characteristic echocardiographic findings [14].

According to Yotsumoto et al, QAV is more common among the group of patients that require replacement of the aortic valve, where $1.46 \%$ of patients that undergo surgery have a QAV [15]. The majority of patients who evolve to aortic insufficiency will need surgery in their fifth or sixth decade [13]. Indications for surgery, whether it is replacement or valvuloplasty, depend on the magnitude of aortic regurgitation [16]. Although, aortic valve replacement is typically the treatment of choice for severe aortic insufficiency, other techniques such as tricuspidization have been implemented. Luciani et al, described bicuspidization to be a more successful technique due to fewer coaptation lines, especially for complex types of QAVs, such as the $\mathrm{G}$ type [17]. The asymmetrical structure of the cusps result in a turbulent flow increasing the risk of infective endocarditis, thus endocarditis prophylaxis is recommended [18].

\section{Conclusions}

QAVs can be difficult to diagnose with transthoracic echocardiography; for this reason 3-D TEE might be required for a detailed description of the cusps size and magnitude of the regurgitation. Despite the fact that this anatomic valve variant is not necessarily pathological, we strongly suggest that assessment of the semilunar valves morphology should be performed in every patient, for an early detection of accompanying cardiac defects and complicating factors such as aortic insufficiency and vegetation growth on the valve. Diagnosis should involve echocardiographic methods as well as computerized tomography and magnetic resonance imaging for a more accurate detection and detailed description of the abnormality. Surgical replacement or valvuloplasty should be reviewed to regain valve function and prevent thromboembolic or hemorrhagic complications. Echocardiographic follow-up in normally functioning QAVs should be considered for prompt identification of functional alterations, therefore enabling the proper therapeutic intervention. Reports associated to QAVs are limited; therefore, we expect a greater amount of information and the implementation of guidelines to treat future cases of supernumerary valve anomalies.

\section{References}

1. Báez A. Válvula aórtica cuadricúspide. Rev Urug Cardiol 2009; 24: 126-127.

2. Holm H, Jacobson S, Reul GJ, Stainback RF. Quadricuspid aortic valve. Tex Heart Inst J 2004; 31: 450-451.

3. Tsukioka K, Nobara H, Takano T, Wada Y, Amano J. Quadricuspid aortic valve with ascending aortic aneurysm: a case report and histopathological investigation. Ann Thorac Cardiovasc Surg 2011; 17: 418-421.

4. Seol SH, Kim U, Cho HJ, Kim DK, Kim DI, Kim DS. Quadricuspid aortic valve with patent ductus arteriosus. Tex Heart Inst J 2010; 37: 726-727.

5. Timperley J, Milner R, Marshall AJ, Gilbert TJ. Quadricuspid aortic valves. Clin Cardiol 2002; 25: 548-552.

6. Fernández B, Durán AC, Martire A, López D, Sans-Coma $\mathrm{V}$. New embryological evidence for the formation of quadricuspid aortic valves in the Syrian hamster (Mesocricetus auratus). J Comp Pathol 1999; 121: 89-94.

7. Hurwitz LE, Roberts WC. Quadricuspid semilunar valve. Am J Cardiol 1973; 31: 623-626.

8. Bakirci EM, Arslan S, Degirmenci H, Sevimli S. A quadricuspid aortic valve causing moderate aortic regurgitation. Cardiol J 2012; 19: 632-634.

9. Vizzardi E, Fracassi F, Nardi M, et al. Asymptomatic quadricuspid aortic valve. Can J Cardiol 2008; 24: e8.

10. Youn YJ, Kim JY, Harn SW,et al. A case of quadricuspid aortic valve with aortic regurgitation. J Cardiovasc Ultrasound 2010; 18: 70-71.

11. Ozlü MF, Ozcan F, Cagli K, Gölbasi Z. Quadricuspid aortic valve in a patient with mitral valve prolapse. Can J Cardiol 2008; 24: e27.

12. Zhu J, Zhang J, Wu S, Zhang Y, Ding F, Mei J. Congenital quadricuspid aortic valve associated with aortic insufficiency and mitral regurgitation. J Cardiothorac Surg 2013; 8: 87.

13. Tutarel $\mathrm{O}$. The quadricuspid aortic valve: a comprehensive review. J Heart Valve Dis 2004; 13: 534-537.

14. Gouveia S, Martins JD, Costa G, et al. Quadricuspid aortic valve--10-year case series and literature review. Rev Port Cardiol 2011; 30: 849-854.

15. Yotsumoto G, Iguro Y, Kinjo T, Matsumoto H, Masuda H, Sakata R. Congenital quadricuspid aortic valve: report of nine surgical cases. Ann Thorac Cardiovasc Surg 2003; 9: 134-137.

16. Formica F, Sangalli F, Ferro O, Paolini G. A rare cause of severe aortic regurgitation: quadricuspid aortic valve. Interact Cardiovasc Thorac Surg 2004; 3: 672-674.

17. Luciani GB, Morjan M, Faggian G, Mazzucco A. Repair of quadricuspid aortic valve by bicuspidization: a novel technique. Interact Cardiovasc Thorac Surg 2010; 11: 348-550.

18. Bauer F, Litzler PY, Tabley A, Cribier A, Bessou JP. Endocarditis complicating a congenital quadricuspid aortic valve. Eur J Echocardiogr 2008; 9: 386-387. 